\title{
Information-seeking Behavior of Physical Science Librarians: Does Research Inform Practice?
}

\section{Cecelia M. Brown and Lina Ortega}

\begin{abstract}
Physical science librarians rely on personal communication and online discussion groups for information to enlighten their practice. Scholarly journals appear third on the list of resources used to inform daily activities and are used primarily to support information literacy instruction, subscription decisions, and their own research as well as to learn about best practices in other libraries. The preferred library and information studies journals publish virtually equal proportions of research and nonresearch articles, with the majority of research articles being reports of qualitative surveys without statistical analysis. The popular journals were not those most highly cited, nor were the research articles cited to a greater extent than the nonresearch articles. In essence, the experiences and opinions of colleagues and patrons were found to be of greater value to the practice of physical science librarianship than reports of original research.
\end{abstract}

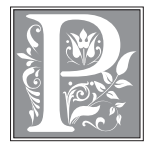

hysical science librarians act as the gatekeepers to the literature of chemistry, physics, astronomy, mathematics, and geosciences. These exceptionally information-literate and technologically savvy information professionals are able to extract even the most esoteric of information from a wide range of print and electronic resources. Not only are physical science librarians able to mine the vast body of physical science information successfully, but they also make daunting decisions about which of the often exorbitantly priced physical science information resources to acquire for their institutions. Added to these tasks is the charge of instructing physical science students, faculty, and researchers in the use of information resources.

Clearly, physical science librarians are required to possess a wide range of abilities, yet how they gain the knowledge to carry out their panoply of charges beyond the attainment of a master's degree is not well understood or documented. This article presents the results of a study of the information-seeking activities used by physical science librarians to inform their practice. The results are part of a larger investigation that also profiled the level of education and experience and the re-

Cecelia M. Brown is an Associate Professor in the School of Library and Information Studies at The University of Oklahoma; e-mail: cbrown@ou.edu. Lina Ortega is an Assistant Professor and Chemistry-Mathematics Librarian in the University Libraries at The University of Oklahoma; e-mail: lortega@ou.edu. The authors gratefully acknowledge Charles Bender for maintenance of the online survey and Kristie Boucher for preparing it for distribution. 
search interests and publication requirements of physical science librarians in the United States, Canada, and abroad. ${ }^{1}$ It was hypothesized that the information-seeking behavior of this cohort of librarians parallels that of their colleagues in the physical sciences, where experimental evidence published in the peer-reviewed research literature has been the timehonored vehicle for the dissemination of information research results. ${ }^{2}$ However, it also is assumed that physical science librarians are similar to mathematicians in their reliance on information that is shared within the peer group to assist in the delivery of products and services to their patrons. ${ }^{3}$

Librarians have been collecting data about their patrons' information usage since the early 1930s, yet the data often go unpublished or unread. ${ }^{4}$ Use of research evidence to inform practice enables the process of decision making for librarians by circumventing the need to "reinvent the wheel" and by drawing on the experience and expertise of others when faced with a new situation. Researchbased and data-driven decision making in librarianship not only saves time and duplication of effort, but it also enriches practice by assisting practitioners in forecasting future developments and trends. In addition to the advantages reaped by utilizing the research literature of librarianship, librarians' active involvement in research projects and publication activities serves to deepen their understanding of user information behavior and needs. This knowledge empowers librarians to create and effect change in order to improve and enhance information products and services. Despite the positive returns, however, the practice of using the research literature of librarianship is stymied not only by the lack of time and institutional commitment, but also due to both a lack of a solid research identity in the profession and the questionable rigor of the research published. ${ }^{5}$ Despite these criticisms, investigations have found that public library leaders realize the value of quantitative research as a management tool but have difficulty keeping up with the research literature. ${ }^{6}$ Correspondingly, Ronald J. Powell, Lynda M. Baker, and Joseph J. Mika found that approximately 90 percent of library practitioners from a wide range of professional societies regularly read at least one research journal, but only 50 percent of the respondents apply the knowledge gained to their practice. ${ }^{7}$

Currently, the concept of basing the practice of librarianship on research results is enjoying resurgence in popularity, especially among medical librarians, under the label of evidence-based librarianship. ${ }^{8}$ Moreover, several editorials in the literature of librarianship have called for the development of evidence-based practice in the field as a whole. ${ }^{9}$ The renewed emphasis on research informing practice is further exemplified by the new SLA Research Statement calling for development of a research base in special librarianship. ${ }^{10}$ Similarly, the ALA's Task Force on Core Competencies Draft Statement purports that demonstrated knowledge of the research process is critical to the success of librarians working in academic, public, school, and special libraries and information centers. ${ }^{11}$ The impact of these statements is reflected in the series of papers on evidence-based librarianship presented at both the ALA and SLA 2004 Annual Conferences. ${ }^{12}$ However, to date, the information-seeking behavior employed by physical science librarians to find evidence on which to base their daily practice has not been studied specifically.

The literature of librarianship itself has been subjected to a degree of scrutiny for the occurrence of research articles over the past two decades. Patricia E. Feehan et al. characterized only 24 percent of articles appearing in ninety-one library and information science (LIS) journals in 1984 as research articles. ${ }^{13}$ Similarly, Lois Buttlar discovered the majority of articles published from 1987 to 1989 in sixteen LIS journals to be news announcements, letters, and descriptive or opinion papers 


\begin{tabular}{|l|l|c|}
\hline \multicolumn{3}{|c|}{$\begin{array}{c}\text { TABLE 1 } \\
\text { Online Discussion Lists }\end{array}$} \\
\hline \hline \multicolumn{1}{|c|}{ Sponsoring Organization } & \multicolumn{1}{c|}{ Group } & $\begin{array}{c}\text { Estimated No. } \\
\text { of Subscribers }\end{array}$ \\
\hline American Library Association & Science and Technology Section & 1,097 \\
\hline $\begin{array}{l}\text { American Society for Information } \\
\text { Science \& Technology }\end{array}$ & $\begin{array}{l}\text { Science and Technology Informa- } \\
\text { tion Special Interest Group }\end{array}$ & 263 \\
\hline Special Library Association & Chemistry Division & 1,400 \\
\hline & $\begin{array}{l}\text { Physics-Astronomy-Mathematics } \\
\text { Division }\end{array}$ & 520 \\
\hline American Geological Institute & Geoscience Information Society & 280 \\
\hline
\end{tabular}

rather than research reports. ${ }^{14}$ More recently, Rebecca Watson-Boone analyzed twenty-four Journal of Academic Librarianship articles from 1985 to 1995 in order to define the types of research conducted by academic librarians. ${ }^{15}$ Fifty percent of the research articles were characterized as survey research and the rest were either action research $(21 \%)$, secondary data analysis $(12.5 \%)$, case studies $(8.3 \%)$, evaluation research $(4.2 \%)$, or experimental $(8.2 \%)$. The content of articles in the LIS journals primarily read by physical science librarians has not been subjected to such in-depth investigation.

To delve into the research literature use by physical science librarians, this investigation used a combination of qualitative and quantitative measurements. A questionnaire focusing on the quest for information to inform practice was distributed electronically to physical science librarians in the United States, Canada, and abroad. Subsequent content analysis of the journals reportedly to be most highly read by the physical science librarians responding to the survey was conducted for the years 1995, 1997, and 2000 to obtain a picture of the type of research articles published in those wellregarded journals over time. Additionally, to measure the extent to which the level of use reported by the respondents is mirrored in the periodical literature, citation analyses were conducted of all the articles published in the highly read journals. The information gleaned from this study will serve to inform a range of practitioners of the actual and potential utility of the research literature in the practice of physical science, as well as other types of librarianship.

\section{Methodology \\ Online Survey}

An online survey was disseminated in March of 2004 to inquire about the subjects' use of the research literature in their practice of librarianship. The questionnaire probed the reading practices of physical science librarians and their perceptions of the transferability of research results to their daily practice. The population surveyed was the international group of subscribers to online discussion lists of interest to physical science librarians that are sponsored by a variety of organizations. (See table 1.)

\section{Literature Analysis}

The literature analysis component of the study used both citation and content analyses of the library literature. Journals designated as highly read by the subjects surveyed were analyzed for the number of citations to both research-oriented as well as "other," nonresearch articles using the Institute for Scientific Information's (ISI's) online citation index, the Web of Science. ${ }^{16}$ Information about the journals also was collected from Ulrich's Periodical Directory in order to categorize the types of journals highly read by physical science librarians. ${ }^{17}$ To gain a view of the 


\begin{tabular}{|c|c|c|}
\hline Categori & $\begin{array}{c}\text { TABLE } 2 \\
\text { s of Library Science Re }\end{array}$ & earch Articles \\
\hline Tier I. Research Method & & \\
\hline A. Experimental & & \\
\hline B. Survey & & \\
\hline C. Historical & & \\
\hline D. Operations & & \\
\hline & Tier II. Data Collection & \\
\hline & A. Qualitative & \\
\hline & i. Statistical analysis & \\
\hline & ii. No statistical analysis & \\
\hline & B. Quantitative & \\
\hline & i. Statistical analysis & \\
\hline & ii. No statistical analysis & \\
\hline & & Tier III. Technique \\
\hline & & A. Case study \\
\hline & & B. User study: \\
\hline & & i. Transaction log analysis \\
\hline & & ii. Circulation data \\
\hline & & iii. Attitude \\
\hline & & C. Evaluation research \\
\hline & & i. Programs and services \\
\hline & & ii. Collection \\
\hline & & iii. Usability \\
\hline & & iv. Educational outcomes \\
\hline & & D. Content analysis \\
\hline & & E. Citation analysis \\
\hline & & F. Methodology description \\
\hline
\end{tabular}

pattern of publication and citation of library science research articles over time, journals from three years were examined. As the number of citations is consistently observed to peak two to three years following publication, the content and citation analysis were confined to 1995 , 1997, and 2000 to ensure meaningful citation data. ${ }^{18}$

In order to depict the extent of the range of methodologies used in library and information studies, research articles were categorized according to the methodology employed using the types of library research described by Charles H. Busha and Stephen B. Harter as a guide. ${ }^{19}$ First, the articles were designated as research or "other" articles, with those designated as "other" articles being descriptive or opinion pieces. The research articles then were classified according to the broad umbrella of research methodologies listed in the first tier of table 2. The studies were divided further into those that collected qualitative versus quantitative data as listed in the second tier. At this point, the studies were examined for the use of statistical 


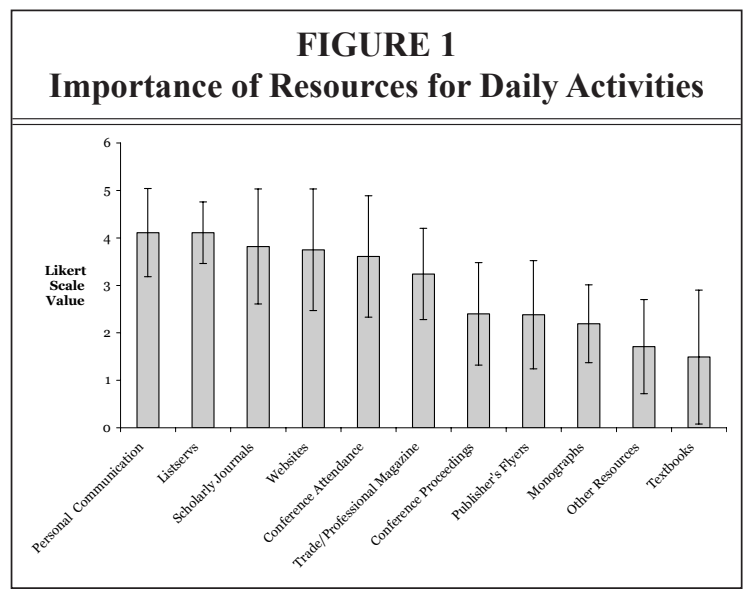

66 percent of the physical science librarians reporting being in the field for more than ten years.

\section{Use of Resources}

Responses to the survey indicate that physical science librarians place a significantly higher value on the invisible college as an information resource for their daily activities than the journal literature. (See figure 1.) Personal communication and listservs were rated as the most important

analysis. Finally, the articles were sorted according to the techniques employed as listed under the third tier in table 2. For example, a research project that uses surveys asking chemists to rate on a Likert scale how well their institution's library fulfils their research needs and analyzes the data using a Chi-squared analysis will be designated as a survey that uses qualitative data collection with statistical analysis to evaluate a collection.

Comparisons and contrasts then were made between the usage reported by practitioners in the field and the data collected from the content and citation analyses.

\section{Results}

\section{Demographics}

A total of seventy-two physical science librarians responded to the online questionnaire. Although only a small fraction of the total number of the list subscribers responded to the questionnaire, the consistency of the answers received suggest that those responding provide a representative snapshot of the current research practices of physical science librarians. The majority of the respondents (85\%) work in an academic institution, with 53 percent having held their current position for five years or less. Despite the short duration of time in their present position, the survey population was very experienced in the field of librarianship, with resources, followed by scholarly journals, Web sites, conference attendance, and trade/professional magazines. The differences among the mean rankings for each resource were found to be significantly different using the Friedman test with $p<0.0005$. Having ranked the resources, the librarians then were asked to gauge the importance of these resources overall, as well as the LIS literature, to their practice. The average rating for all resources was $3.9 \pm 0.68$ on a scale of 1 (minimal importance) to 5 (extensive importance) to the librarians' daily activities. LIS research literature was considered to be of significantly $(\mathrm{p}<0.0005)$ less importance to daily practice than these other methods of communication listed $(2.9 \pm 1.18)$ using a Wilcoxon Signed Ranks Test. This was reflected in the small amount of time (less than five hours per week) spent reading LIS journals by 86 percent of the respondents. Other resources listed by the survey participants include newsletters (online and print), book reviews, and patents and subject bibliographies.

It is interesting to note the variations observed in the respondents' ratings of the importance of information resources to their practice in relation to the number of years in their current position and number of years of experience in the field. (See figure 2.) Although the differences in average importance ratings according to years in current position and years of 
experience were not shown to be statistically significant using the Friedman ( $p>0.1)$ test, the graphs nonetheless point to different usage of the various information resources over time. The ratings of importance for all resources tended to decline the longer the physical science librarians remained in their current position, except for a small transient increase in the importance of the resources for those who have been in their current position for six to ten years. The importance of all sources of information remained fairly constant as the librarians' years of experience increased. In contrast, the survey participants indicated that LIS research literature became less important as they gained more experience, with the excep-

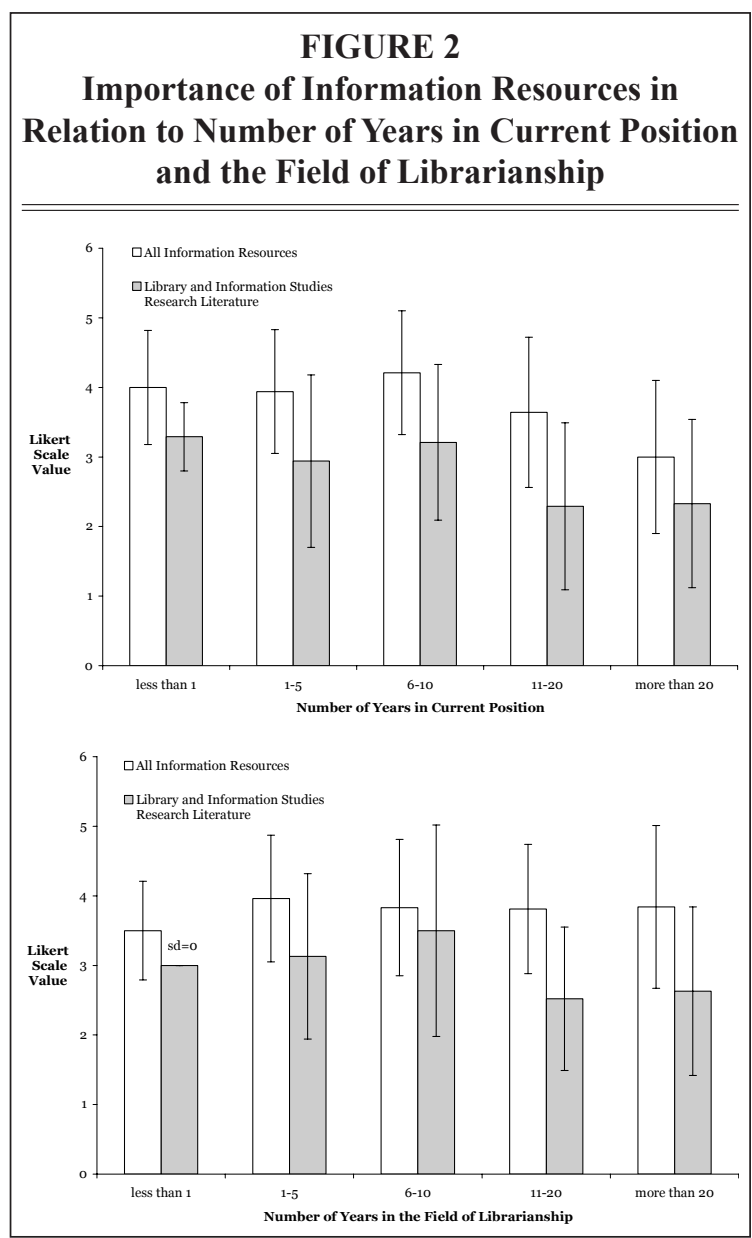

tion again being those who have been in the field for six to ten years. The reason for the small increases in importance of information resources for those in this middle range of tenure and experience is unknown. Perhaps by this midstage of their career, physical science librarians have learned the basics of their position and, as a result, have more time to consult LIS research literature and other resources to assist their practice.

Even though physical science librarians seek out personal communication channels to inform their practice, when asked to describe their most recent application of the research literature, the majority of respondents were able to provide at least one reason. Several reported using the literature to help them prepare for information literacy instruction and to learn about instructional technologies $(21 \%)$. Others reported recently reading the LIS research literature to assist in subscription decisions (12\%) and to inform their own research $(11 \%)$, a surprisingly low figure considering that 43 percent of the respondents indicated that they are required to conduct research and 38 percent are required to publish. Eleven percent of the respondents used the literature to glean information about best practices, such as how to use, implement, and cope with various technologies, especially digital reference service. However, seven respondents made no comment on their usage and four claimed not to use the research literature because they do not have time or do not find it of relevance to their position. Other uses of the LIS research literature, reported by less than four percent of the respondents, 
Information-seeking Behavior of Physical Science Librarians 237

\begin{tabular}{|c|c|c|c|c|c|c|c|c|c|c|}
\hline & 离 & & $\begin{array}{l}\text { *ै } \\
\text { مू }\end{array}$ & $\begin{array}{l}\stackrel{\infty}{2} \\
\stackrel{=}{=}\end{array}$ & $\frac{n}{2}$ & $\stackrel{8}{\circledR}$ & $\begin{array}{l}0 \\
0 \\
0\end{array}$ & $\stackrel{\infty}{\stackrel{\infty}{2}}$ & $\frac{0}{2}$ & బั \\
\hline & 莡 & $\sum^{\infty}$ & $\sum_{\nu}^{\infty}$ & $\stackrel{\infty}{\nu}$ & $\sum_{\nu}^{\infty}$ & $\stackrel{\theta}{2}$ & $\stackrel{\circ}{z}$ & $\stackrel{0}{\infty}$ & Z & $\stackrel{0}{0}$ \\
\hline & 咅言 & 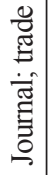 & 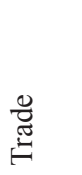 & 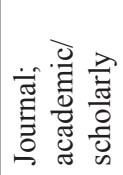 & 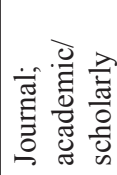 & 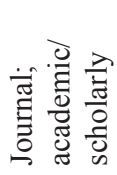 & \begin{tabular}{l}
$\frac{0}{\tilde{T}}$ \\
\multirow{\pi}{*}{}
\end{tabular} & 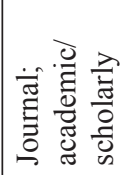 & 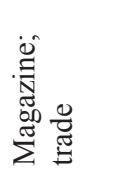 & 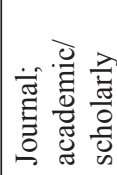 \\
\hline 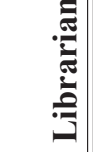 & 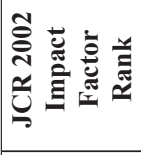 & $\underline{\Xi}$ & $\mid$ & $\mid$ & 咅 & $\frac{\vec{n}}{\vec{n}}$ & $\mid$ & m & $\mid$ & $\underset{\infty}{\infty}$ \\
\hline 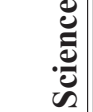 & 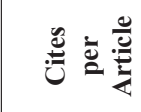 & $\hat{a}$ & 1 & $\mid$ & $\stackrel{r}{\dot{\gamma}}$ & ָָ & 1 & $\stackrel{0}{\stackrel{1}{2}}$ & $\mid$ & $\stackrel{\nabla}{\ddot{n}}$ \\
\hline 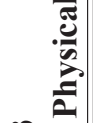 & 气ิે & లn & | & | & กn & m & $\mid$ & \& & $\mid$ & $F$ \\
\hline $\begin{array}{ll}\frac{1}{2} & 0 \\
\overline{7} & \bar{J}\end{array}$ & 气ิે & $\begin{array}{l}n \\
n \\
n\end{array}$ & $\mid$ & $\mid$ & $\stackrel{n}{\sim}$ & $\mathbb{N}$ & $\mid$ & $\begin{array}{l}\infty \\
\infty \\
\infty \\
0\end{array}$ & | & สี \\
\hline & 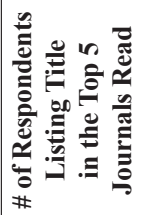 & $n$ & নे & $\vec{\sim}$ & $\cong$ & $\stackrel{0}{0}$ & $\infty$ & $\infty$ & 6 & 6 \\
\hline 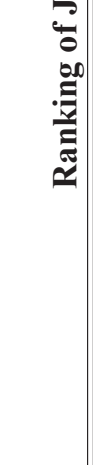 & 产 & 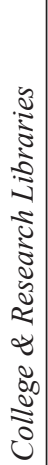 & 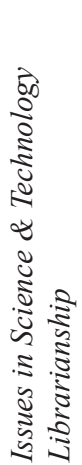 & 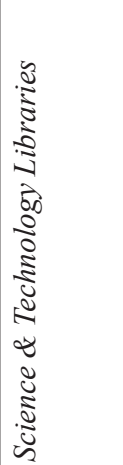 & 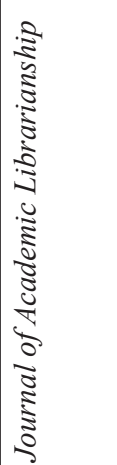 & 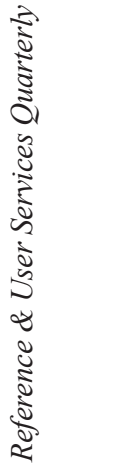 & 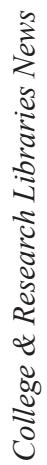 & 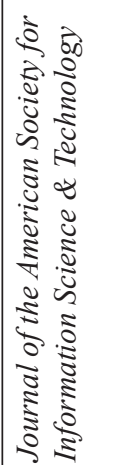 & 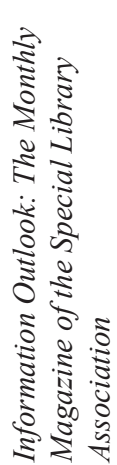 & 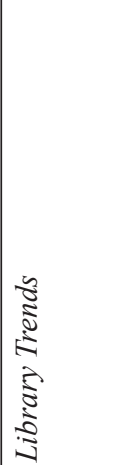 \\
\hline & 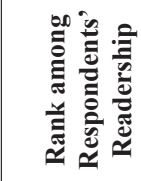 & - & $N$ & $m$ & $\nabla$ & $n$ & 6 & $r$ & $\infty$ & $a$ \\
\hline
\end{tabular}




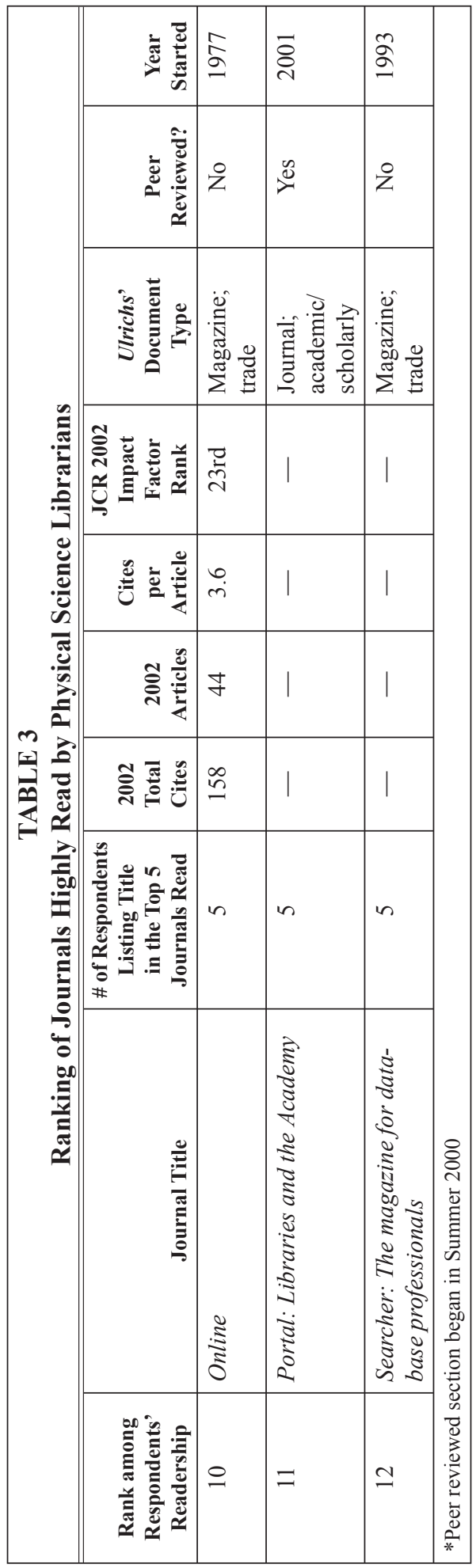

included finding information to support decisions concerning collection development/management, reference, and remodeling or space design.

About half the survey respondents $(49 \%)$ provided additional comments about the LIS research literature and how it influences their daily activities. Several $(n=15)$ of the comments indicated that published research in LIS is useful to their practice. Some respondents $(\mathrm{n}=$ 9) believe that the literature represents a network of colleagues and their best practices; others $(n=3)$ simply enjoy the scholarly pursuit of further knowledge. A few respondents $(n=3)$ find published research useful, but their workload and lack of institutional support prevent them from engaging in research themselves. Conversely, some respondents (n $=8$ ) do not find LIS research useful because they think the published material contains little of practical value or is of marginal quality. These additional comments illustrate the ambiguous status of research in the LIS profession.

\section{Journals Read}

Table 3 lists the top twelve most highly read journals with their rankings from ISI's Journal Citation Reports and their document type according to Ulrich's Periodical Directory. ${ }^{20}$ Forty-nine percent of the seventy-two respondents listed College $\mathcal{E}$ Research Libraries (CERL), a trade journal, in the top five journals read regularly. Issues in Science and Technology Librarianship (ISTL), a trade publication, was the second most highly read periodical $(40 \%)$, and Science and Technology Libraries (SETL), an academic/ scholarly journal, ranked third (29\%). Six additional academic/scholarly journals appeared in the top twelve in addition to four trade publications. It appears that physical science librarian readership is not restricted to one category of publication type but, rather, encompasses a broad range of journals.

Similarly, the journal readership data are not reflective of ISI's Journal Citation 
Reports impact factor-ranking data (table 3). ${ }^{21}$ Not all of the highly read journals are ranked by ISI, nor do all the journals most highly ranked by ISI appear on the physical science librarians' favored titles list. $C \mathcal{E} R L$, rated tenth by ISI, is the journal most widely read by the physical science librarians responding. The next two most highly read journals, ISTL and $S \mathcal{E} T L$, are not rated by ISI. Conversely, MIS Quarterly and Annual Review of Information Science and Technology head the ISI impact factor list but are not regularly read by the seventy-two physical science librarians responding to the survey. The Journal of the American Society for Information Science and Technology (JASIST), which ranks third on the ISI list, falls to seventh in the readership order of the physical science librarians surveyed. These findings suggest that physical science librarians read what is of interest to them, rather than what is highly cited, and do not necessarily cite what they are reading regularly.

The librarians also were given the opportunity to list journals from other fields that they read on a regular basis. The journals Science and Nature were listed by twenty-two and twenty-one respondents, respectively. Also listed were Chemical $\mathcal{E}$ Engineering News, American Society for Engineering Education Prism, and Chronicle of Higher Education. It is interesting to note that when reading outside the field of librarianship, the physical science librarians reported reading what is highly ranked by ISI. ${ }^{22}$ This information-seeking behavior is likely due to the high relevance, broad coverage, and extraordinary readability of the information published in these journals, which in turn facilitate the physical science librarians' ability to stay up to date with recent developments in their patrons' fields.

\section{Content Analysis}

Content analysis was conducted on the six most highly read journals plus Library Trends (LT). It was decided to confine the analysis to this set of journals because they represent the journals read by at least 10 percent of the respondents and also because those remaining in the top twelve were not

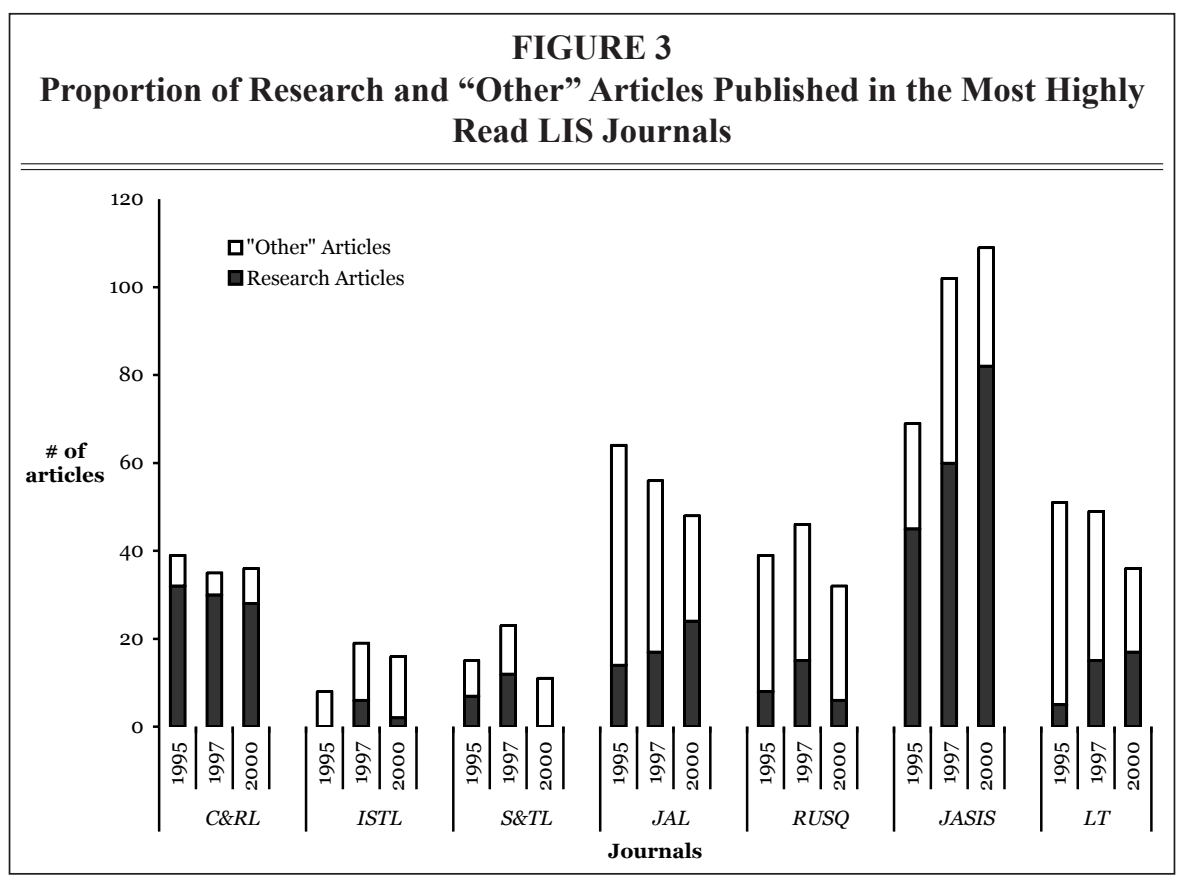




\section{FIGURE 4}

Data Collection Methods Used by the Authors of the Research Articles Appearing in the Most Highly Read LIS Journals in 1995, 1997, and 2000

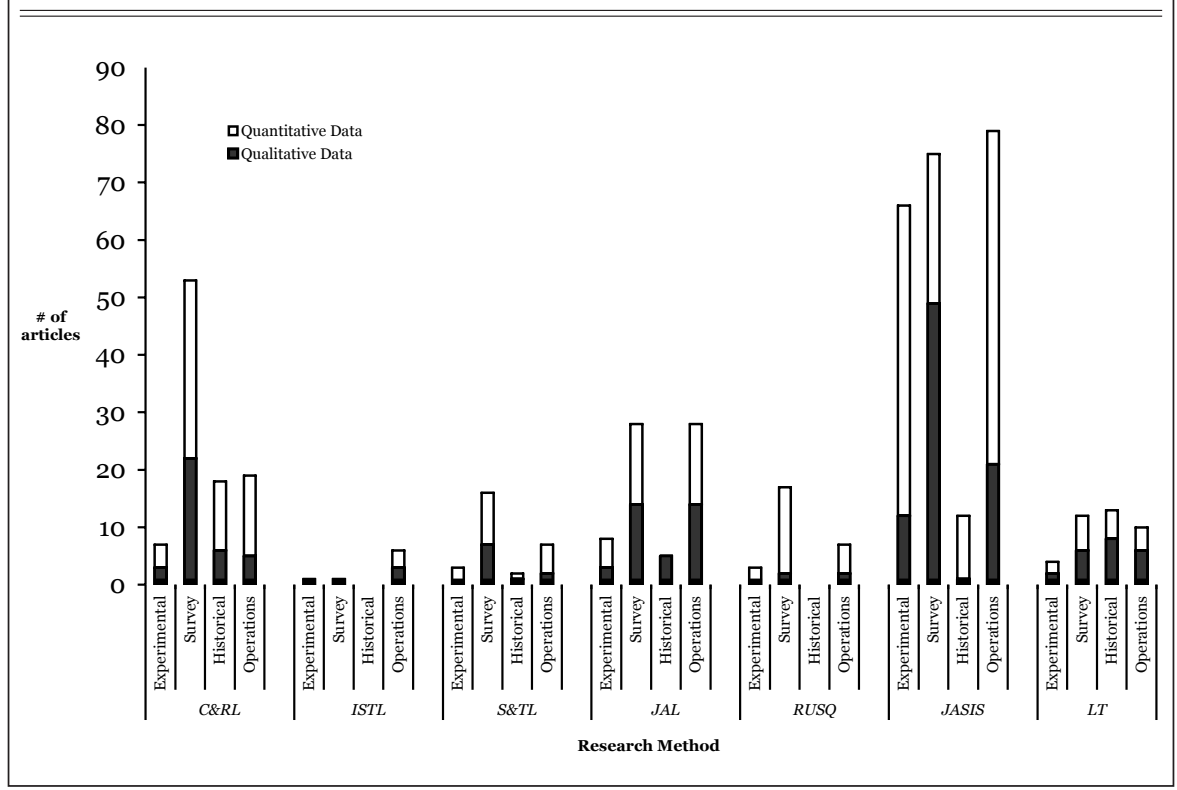

ranked by ISI and/or not classified as scholarly/academic journals by Ulrich's. ${ }^{23}$ Figure 3 illustrates the proportion of research (47\%) and "other" (53\%) articles published in this microcosm of journals during 1995, 1997, and 2000. The journals CERL and JASIS published the highest proportion of research to "other" articles whereas the other journals analyzed published a greater number of non-research-oriented papers than research articles. The journal Library Trends (LT) also published fewer research articles than "other" articles in 1995 and 1997 but printed virtually an equal number of research and "other" articles in 2000. A gradual increase in total number of publications in JASIS was observed from 1995 to 2000, but a decrease in the number of papers in $J A L$ and $L T$. It is interesting to note that these changes in numbers of articles published were accompanied by an increase in the total number of research articles published in these three journals. However, because no distinct trend was observed in the number of articles published in the entire population of journals over the time span studied, the data for all three years were pooled for the remainder of the content analyses.

The articles that were identified as research-oriented publications were classified according to the research method used (Tier I), then data collection method used (Tier II), and finally the technique used to collect the data (Tier III). The results of the examination of the articles for the research methods and data collection approaches used by the research article authors are presented in figure 4 . Survey research was found to be the predominant type of research methodology (40\%). Thirty-one percent of the research articles used operations research methods whereas 18 percent and 11 percent of the remaining articles used experimental and historical research methods, respectively. Sixty-two percent of the research articles collected quantitative data. This overall pattern holds true for all the journals studied except $J A L$ and $L T$, where fewer $(48 \%$ and $40 \%$, respectively) of the research articles collected quantitative data. 
The research method used appears to dictate to some extent the type of data collected. Seventy-nine percent of the studies using an experimental method and 57 and 65 percent of the studies using historical and operations research methods collected quantitative data. In contrast, approximately equal numbers of the studies using the popular survey techniques collected quantitative (52\%) and qualitative (48\%) data. Sixty-seven percent of all the studies collecting quantitative data used statistical analysis to help interpret the results, compared to only 33 percent of the qualitative studies. Fewer articles using the favored survey technique to collect quantitative data employed statistics (42\%), compared to articles using other types of methodologies. However, surveys collecting qualitative data used statistics to the same extent $(33 \%)$ as the other studies gathering qualitative information. The types of statistical analyses performed ranged from calculations of means to complex multivariate regression analyses. Although the umbrella of research methods and data collection techniques in the highly read journals is broad and multifaceted, the content analyses suggest that the journals most highly read by physical science librarians publish primarily survey research that reports both qualitative and quantitative results that have been limitedly subjected to statistical analysis.

To further characterize the types of research articles read by physical science librarians, each article was examined for the technique employed as described in Tier III of table 2 (figure 5). Several studies used more than one technique to solve the problem at hand for a total of 719 techniques spread across the 439 research articles examined. User studies comprised 31 percent of the techniques used with the majority (77\%) reporting users' attitudes and opinions. Evaluation research techniques contributed to a similar proportion $(29 \%)$ of the total techniques employed, with usability studies being the primary mode utilized (39\%) within this category, especially in JASIS where 76 percent of the evaluation research articles were usability studies. Finally, examination of the third tier shows that descriptions of methodologies were a distant third (14\%) in the list of all the techniques employed; case studies $(12 \%)$, content analyses $(10 \%)$, and citation analysis $(4 \%)$ were employed with even less frequency. Noteworthy is the predominance of methodology descriptions (29\%) and content analysis (21\%) in the Tier III articles published in JASIS, especially in comparison to those in the other journals analyzed.

This final step in the exploration of the content of research articles in the journals highly read by physical science librarians points to the opinions and attitudes of human subjects as the primary technique used to gather data regardless of the LIS journal analyzed. Taking this into consideration with the categories from Tiers I and II, physical science librarians have a tendency to read journals that publish articles employing survey studies that collect both qualitative and quantitative data that are unlikely to be analyzed statistically.

\section{Citation Analysis}

The final piece in this study was the citation analysis of the journals most highly read by the physical science librarians. The same journals from the same three years that underwent content analysis also were subjected to citation analysis. Figure 6 presents the number of citations per article for each of the three years studied. Using a t-test, the average number of citations received by all the research articles during the three years $(4.49 \pm 4.3)$ was found to be significantly greater $(p<0.001)$ than the number of citations received by the "other" articles (2.31 \pm 2.7$)$. When each journal was examined individually, however, only the average number of citations garnered by the research articles in JASIS (8.25 \pm 6.5$)$ during 1995, 1997, and 2000 was found to be significantly greater $(p<.01)$ than the non-research-oriented articles (5.15 \pm 5.1). 


\section{FIGURE 5}

Number of Articles Employing Tier III Techniques in the Most Highly Read LIS Journals during 1995, 1997, and 2000
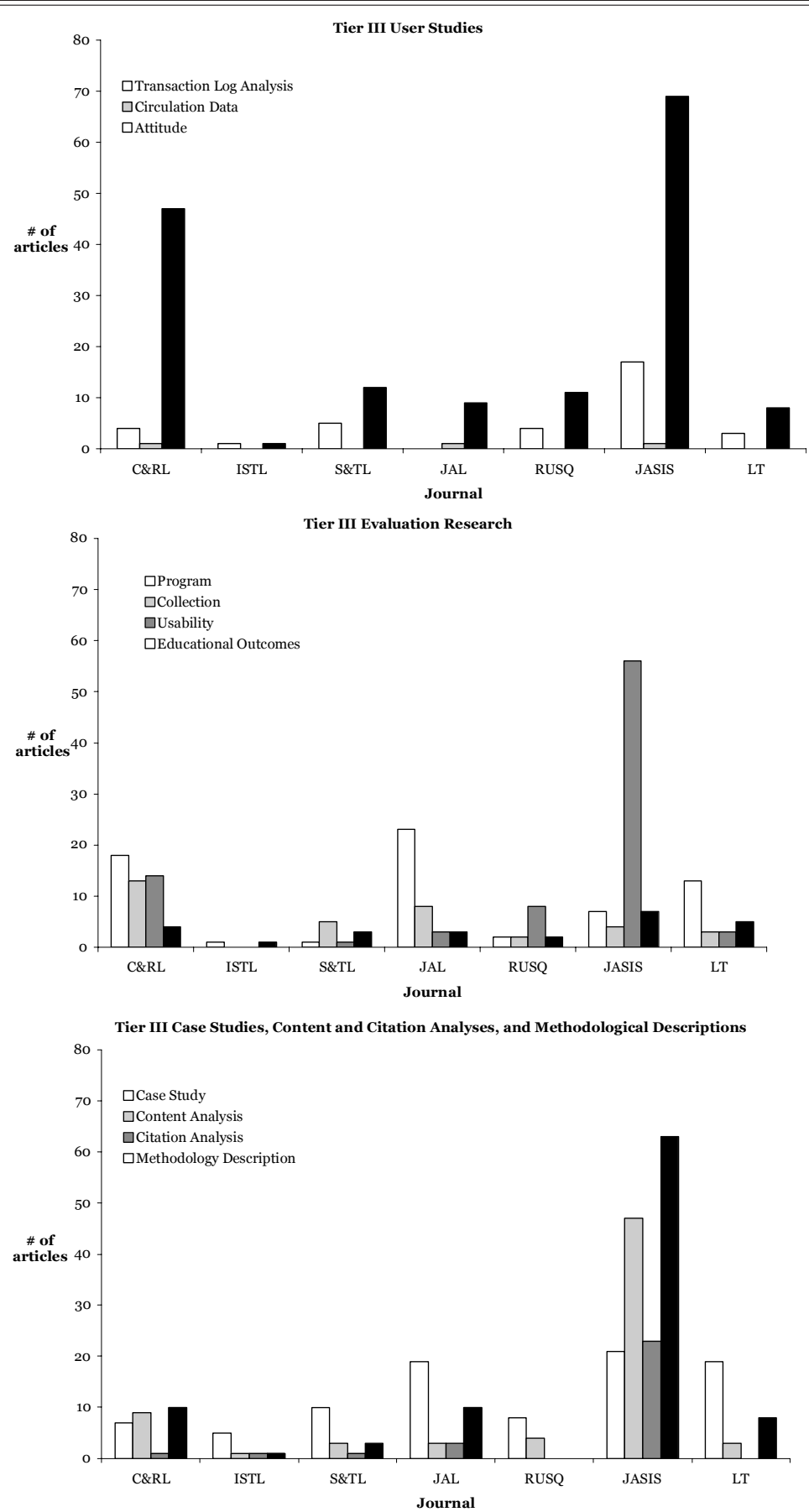
Such an impact may be due in part to the larger proportion of research articles (66\%) in the JASIS articles examined compared to that in the remaining journals (37\%). Similar to the phenomena observed in the content analysis, no distinct pattern of citation rate was observed over the three years examined.

\section{Discussion}

It was originally hypothesized that the information-seeking behavior of physical science librarians would be similar to that of their faculty colleagues in the physical sciences where experimental evidence published in the research literature classically and currently serves to inform their teaching, research, and creative activities. ${ }^{24}$ However, this was not found to be entirely the case for the highly experienced population of physical science librarians responding to the survey. In contrast, the secondary hypothesis that physical science librarians also rely on procedures shared via personal communication both in person and online to inform practice was found to be true. Because the respondents were recruited via listservs and the questionnaire was completed online, it is possible that the survey population was skewed toward those who prefer online communication as their primary mode of information gathering. However, this is balanced by the observation that an equivalent number of respondents also prefer face-to-face communication. Although the physical science librarians' pattern of information seeking parallels that used by mathematicians, the stamp of peer review and citation rate does not appear to influence the utility of information in the practice of physical librarianship to the same extent that it does for the majority of physical scientists. ${ }^{25}$ Like their physical science faculty colleagues, the respondents use the literature primarily to inform their instructional and research activities, but they also read it to find information to assist them in making decisions about subscriptions and to learn about best practices in the field. In essence, although not the primary resource, the research literature does help to support and enhance the daily practice of the majority of physical librarians surveyed.

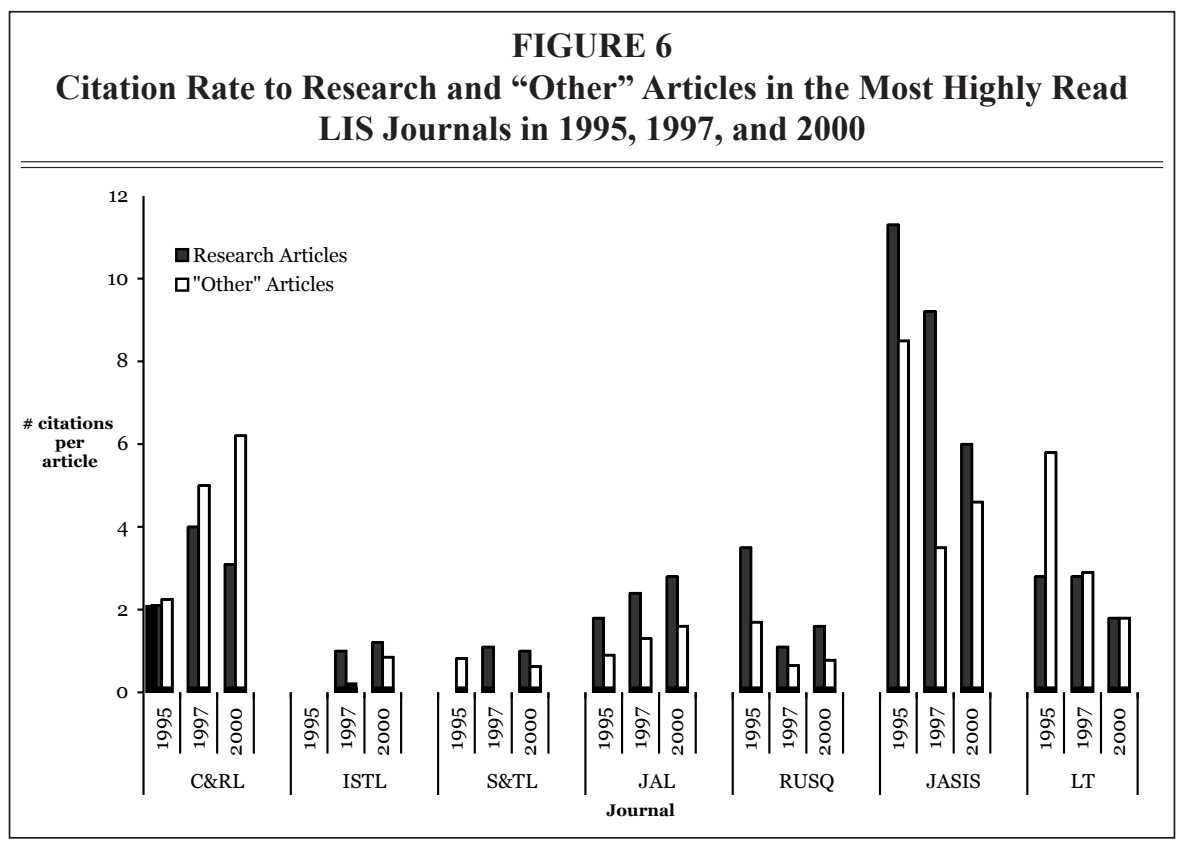


In parallel to these findings, when asked to list the journals read on a daily basis, it is interesting to note that the most highly read publication, CERL, is categorized by Ulrich's Periodical Directory as a trade journal and has a lower ISI impact factor than journals read infrequently by the physical science librarians. ${ }^{26}$ Also noteworthy is that the proportion of research to "other" articles in the highly read journals is virtually equal. Moreover, the citation rate to the two different types of articles is similar when the highly cited JASIS is excluded. Again, these data suggest that the population responding to the survey seeks information from a variety of sources that it finds to be of the greatest use and interest rather than sources that are highly cited and/or the results of a research project.

More than twenty years ago, CERL was ranked first in journal prestige by ARL library directors, but third by deans of LIS schools. ${ }^{27}$ The journals Library Quarterly and JASIS surpassed CERL in prestige rating by the deans but appeared second and sixth, respectively, on the ARL directors' list. Although agreement in David F. Kohl and C.H. Davis's study was considered to be high among the ARL directors and deans, it appears that journal prestige for the ARL directors is similar to that of the practicing physical science librarians in the present study and may be influenced more by a journal's applicability to practice than by the publication of original research. ${ }^{28}$ Indeed, Mary T. Kim subsequently reported that the deans in Kohl and Davis's study placed a higher value on research-oriented publications, but the ARL directors preferred a mix of research-practitioner journals. ${ }^{29}$ Similar to the physical science librarians' data presented here, Kim also found that for ARL directors, citation factors did not influence prestige rating for the highly rated practitioner-oriented journals. ${ }^{30}$ In contrast, however, she did find that citation factors for research journals were correlated with the journal prestige rankings of both ARL directors and deans. ${ }^{31}$
The type of research articles published in the journals preferred by the physical science librarians indicate the high value the respondents place on information that can be applied to their daily activities. Not only is the proportion of research and opinion or descriptive papers virtually equal in the popular journals, but also the research articles appearing in the highly read journals are primarily the results of survey research concerning the opinions and attitudes of human subjects. Feehan et al., Buttlar, and Watson-Boone also found a high number of survey reports in the LIS journal literature published in the 1980s. ${ }^{32}$ The number of articles categorized as research-oriented, however, comprised less than 25 percent of the articles in the journals sampled. ${ }^{33}$ It appears that the number of research articles published in the LIS literature has risen in the past two decades despite the physical science librarians' apparent ambivalence toward their utility in daily practice.

The physical science librarians surveyed are reading journals that publish reports of research that collected both qualitative and quantitative data that may or may not have been scrutinized statistically. In the highly read journals, the type of research conducted appears to affect the type of data collected and their subsequent treatment. Research articles using experimental, historical, and operations research methodologies collected primarily quantitative data compared to only half of the studies using the popular survey technique. Most of the studies collecting quantitative data used statistical analysis to help interpret the results; only one-third of the qualitative studies used statistical analyses. Looking at the articles using the popular survey methodology, it was discovered that less than half of the studies used statistics to interpret the quantitative data collected compared to about one-third of those reporting qualitative results. Similarly, Danny P. Wallace found that the mean number of articles using statistics in twenty-four LIS journals in 1981 was approximately 
26 percent, which was significantly less than the mean number of articles using statistics published in journals from the disciplines of social work, business, and education. ${ }^{34}$ Although it appears that use of statistics and collection of quantitative data in LIS research is on the rise, physical science librarians find useful information for their daily practice in the journal literature whether or not it has been interpreted statistically.

\section{Conclusion}

Physical science librarians in the United States, Canada, and abroad rely primarily on personal communication and online discussion groups for information to assist in their daily practice. These results indicate that for physical science librarians, communication between colleagues serves as their "information ground" or "information community." 35 Their information-seeking behavior does not entirely parallel that of their faculty colleagues in the physical sciences who continue to rely primarily on the time-honored system of peer review and publication in scholarly journals to inform their efforts. ${ }^{36}$ Scholarly journals appeared third on the list of resources used to inform the physical science librarians' routine practice, especially to find information about information literacy instruction, journal subscriptions, and best practice techniques as well as to support their own research. The LIS journals that are most highly read by the physical science librarians publish an almost equal proportion of research and non-research-oriented articles, with the majority of research articles being reports of qualitative surveys without statistical analysis. The most popular journals were not the most highly cited journals, nor were the research articles more highly cited than the nonresearch articles. It is apparent that for physical science librarians, experiences and opinions of colleagues and patrons are of critical importance to their practice and that peer review and citation counts do not necessarily dictate relevance.

Despite the potential benefits, the future and success of basing practice on research evidence remains to be seen for physical science librarianship. A ripe and potentially fruitful area of investigation appears to be the nature and application of the information gleaned from physical science librarians' invisible college of personal communication and online discussion groups. This line of inquiry will shed further light on the information-seeking behavior of physical science librarians with the goal of improving and validating the methods of communication and practice in the field.

\section{Notes}

1. Lina Ortega and Cecelia M. Brown, "The Face of 21st Century Physical Science Librarianship." Submitted for publication, December 2004.

2. Robert K. Merton, "The Matthew Effect in Science," Science 159 (1968): 56-63; William D. Garvey, Nan Lin, and Kazou Tomita, "Research Studies in Patterns of Scientific Communication; III, Information-Exchange Processes Associated with the Production of Journal Articles," in Communication: The Essence of Science. Facilitating Information Exchange among Librarians, Scientists, Engineers and Students, ed. William D. Garvey (New York: Pergamon, 1979), 202-24; Cecelia M. Brown, "Information Seeking Behavior of Scientists in the Electronic Information Age: Astronomers, Chemists, Mathematicians, and Physicists," Journal of the American Society for Information Science 50, no. 10 (1999): 929-43.

3. Brown, "Information Seeking Behavior of Scientists in the Electronic Information Age."

4. Charles H. Busha and Stephen P. Harter, Research Methods in Librarianship: Techniques and Interpretation (New York: Academic Pr., 1980).

5. Alan R. Blick, "Information Science Research versus the Practitioner," in Representation and Exchange of Knowledge as a Basis of Information Process, ed. H. J. Dietchmann (Amsterdam: NorthHolland, 1984), 231-44; Busha and Harter, Research Methods in Librarianship; Charles McClure and Ann Bishop, "The Status of Research in Library/Information Science: Guarded Optimism," College and Research Libraries 50, no. 2 (Mar. 1989): 127-43; Ronald J. Powell, Basic Research Methods 
for Librarians, 3rd ed. (Greenwich, Conn.: Ablex, 1997), 1; Danny P. Wallace and Connie Van Fleet, Library Evaluation: A Casebook and Can-do Guide (Englewood, Colo.: Libraries Unlimited, 2000), xix.

6. William H. Ptacek and Connie Van Fleet, "Public Library Research: The State Agency

Connection," Public Libraries 29 (Sept./Oct. 1990): 277-81; Connie Van Fleet and Joan C. Durrance, "Public Library Leaders and Research: Mechanisms, Perceptions, and Strategies," Journal of Education for Library and Information Science 34, no. 2 (spring 1993): 137-52.

7. Ronald J. Powell, Lynda M. Baker, and Joseph J. Mika, "Library and Information Science Practitioners and Research," Library and Information Science Research 24, no. 1 (2002): 49-72.

8. Jonathan D. Eldredge, "Evidence-based Librarianship: An Overview," Bulletin of the Medical Library Association 88, no. 4 (Oct. 2000): 289-301; Andrew Booth, "Mirage or Reality?" Health Information and Libraries Journal 19 (2002): 56-58; Denise Koufogiannakis and Ellen Crumley, "Evidence-based Librarianship," Feliciter 48, no. 3 (2002): 112-14.

9. John Newman, "Academic Librarians as Scholars," College and Research Library News 59, no. 1 (Jan. 1998): 19-20; Anne Goulding and Graham Matthews, "Editorial: Putting Research into Practice," Journal of Librarianship and Information Science 34, no. 2 (June 2002): 63-66; Kathlyn J. Turner, "The Use of Applied Library and Information Studies (LIS) Research in New Zealand Libraries," Library Review 51, no. 5 (2002): 230-40.

10. "Putting Our Knowledge to Work: A New SLA Research Statement June 2001, The Role of Research in Special Librarianship" (Alexandria, Va.: SLA, 2001). Available online at http://www. sla.org/content/resources/research/rsrchstatement.cfm.

11. "Congress on Professional Education: Focus on Education for the First Professional Degree," Task Force on Core Competencies Draft Statement (Chicago: ALA, 2004). Available online at http://www.ala.org/ala/hrdrbucket/1stcongressonpro/1stcongresstf.htm.

12. "ALA Annual Conference 2004 Preliminary Program," American Libraries 35, no. 3 (Mar. 2004): 89-172; "Conference-At-A-Glance" (Alexandria, Va.: SLA, 2004). Available online at http:// www.sla.org/nashville2004/plannerintro.cfm.

13. Patricia E. Feehan, W. Lee Gragg, W. Michael Havener, and Diane D. Kester, "Library and Information Science Research: An Analysis of the 1984 Journal Literature," Library and Information Science Research 9, no. 3 (July - Sept. 1987): 173-86.

14. Lois Buttlar, "Analyzing the Library Periodical Literature: Content and Authorship," College and Research Libraries 52, no. 1 (Jan. 1991): 38

15. Rebecca Watson-Boone, "Academic Librarians as Practitioner-Researchers," Journal of Academic Librarianship 26, no. 2 (Mar. 2000): 85-93.

16. Institute for Scientific Information, Web of Science (Philadelphia: ISI, 2004).

17. Ulrich's Periodical Directory (New Providence, N.J.: Bowker, 2004).

18. E. S. Aversa, "Citation Patterns of Highly Cited Papers and Their Relationship to Literature Aging: A Study of the Working Literature," Scientometrics 7, no. 3-6 (1985): 383-89; Henk F. Moed, T. H. N. VanLeewem, and J. Reedijk, "A New Classification System to Describe the Ageing of Scientific Journals and Their Impact Factors," Journal of Documentation 54, no. 4 (Sept. 1998): 387-419; Ming-Yueh Tsay, "Library Journal Use and Citation Age in Medical Science," Journal of Documentation 55, no. 5 (Dec. 1999): 543-55; Danny P. Wallace, “The Relationship between Journal Productivity and Obsolescence," Journal of the American Society for Information Science 37, no 3 (Nov. 1985): 136-45.

19. Busha and Harter, Research Methods in Librarianship.

20. Institute for Scientific Information, Journal Citation Reports (Philadelphia: ISI, 2002); Ulrich's Periodical Directory.

21. ISI, Journal Citation Reports.

22. Ibid.

23. ISI, Journal Citation Reports (JCR); Ulrich's Periodical Directory.

24. Merton, "The Matthew Effect in Science," 56-63; Garvey, Lin, and Tomita, "Research Studies in Patterns of Scientific Communication," 202-24; Brown, "Information Seeking Behavior of Scientists in the Electronic Information Age," 929-43.

25. Brown, "Information Seeking Behavior of Scientists in the Electronic Information Age."

26. Ulrich's Periodical Directory; ISI, Journal Citation Reports.

27. David F. Kohl and C. H. Davis, "Ratings of Journals by ARL Library Directors and Deans of Library and Information Science Schools," College and Research Libraries 46, no. 1 (Jan. 1985): $40-47$.

28. Ibid.

29. Mary T. Kim, "Rankings of Journals in Library and Information Science: A Comparison of Perceptual and Citation-based Measures," College and Research Libraries 52, no. 1 (Jan. 1991): 24-37.

30. Ibid., 34-37. 
31. Ibid.

32. Feenhan et al., "Library and Information Science Research," 173-86; Buttlar, "Analyzing the Library Periodical Literature," 38-53; Watson-Boone, "Academic Librarians as PractitionerResearchers," 85-93.

33. Feehan et al., "Library and Information Science Research," 173-86; Buttlar, "Analyzing the Library Periodical Literature," 38-53.

34. Danny P. Wallace, "The Use of Statistical Methods in Library and Information Science," Journal of the American Society for Information Science 36 (Nov. 1985): 402-10.

35. Karen Fisher, "Information Behavior in Everyday Life: Research on Street-level Sex Workers, New Immigrants, and Hair Stylists," Proceedings of the $66^{\text {th }}$ Annual Meeting of the American Society for Information Science and Technology 40 (2003): 464; Karen E. Pettigrew, Joan C. Durrance, and Kenton T. Unruh, "Facilitating Community Information Seeking Using the Internet: Findings for Three Public Library Community Network Systems," Journal of the American Society for Information Science and Technology 53, no. 11 (Sept. 2002): 894-903.

36. Merton, "The Matthew Effect in Science," 56-63; Garvey, Lin, and Tomita, "Research Studies in Patterns of Scientific Communication," 202-24; Brown, "Information Seeking Behavior of Scientists in the Electronic Information Age," 929-43. 